\title{
$\mathrm{M} 2 \mathrm{M}$ 기술을 이용한 스마트 선박 컨테이너
}

\author{
로네쉬 샤르마, 이 성 로
}

\section{Smart Ship Container With M2M Technology}

\author{
Ronesh Sharma*, Seong Ro Lee
}

요 약

현대 정보 기술은 새롭고 개선된 방법으로 여러 산업들에 지속적인 제공을 하고 있다. 본 논문에서 고려한 스 마트 컨테이너 공급망 관리는 사물지능(M2M)통신의 급속한 발전과 함께 고성능 센서, 컴퓨터 비전, GPS, GSM 을 기반으로 형성된다. 기존 공급망관리는 실시간 컨테이너 추적에 제한이 있다는 문제점을 가지고 있다. 본 논문 은 인터럽트 및 보통 정기적인 알림에 대한 컨테이너 식별 시스템과 자동 알림 시스템의 개발과 실시간 컨테이너 공급망관리의 연구 및 구현에 초점을 맞추었다. 첫째, 본 논문은 컨테이너 코드 식별 및 실시간 작업에 대해 컴퓨 터 비전 라이브러리와 OCR 엔진을 비주얼 스튜디오 2010으로 구현된 식별 알고리즘을 제안하고 있다. 둘째는 실 시간 컨테이너 추적 및 그 시스템의 한계에 대해 제공되는 현재 자동 알림 시스템에 대해 설명한다. 마지막으로 본 논문은 고성능 센서와 컴퓨터 비전과 함께 유비쿼터스 모바일 및 위성 네트워크와 실시간 컨테이너 추적 솔루 션의 미래에 도전과 가능성을 요약하였다. 뛰어난 운영 및 보안 공급망관리의 우수한 전송을 제공하기 위해 이러 한 모든 구성요소를 결합하였다.

Key words : Container Identification, Opencv, Tesseract, M2M , Automatic Alert System, Smart Container

Abstract

Modern information technologies continue to provide industries with new and improved methods. With the rapid development of Machine to Machine (M2M) communication, a smart container supply chain management is formed based on high performance sensors, computer vision, Global Positioning System (GPS) satellites, and Globle System for Mobile (GSM) communication. Existing supply chain management has limitation to real time container tracking. This paper focuses on the studies and implementation of real time container chain management with the development of the container identification system and automatic alert system for interrupts and for normal periodical alerts. The concept and methods of smart container modeling are introduced together with the structure explained prior to the implementation of smart container tracking alert system. Firstly, the paper introduces the container code identification and recognition algorithm implemented in visual studio 2010 with Opencv (computer vision library) and Tesseract (OCR engine) for real time operation. Secondly it discusses the current automatic alert system provided for real time container tracking and the limitations of those systems. Finally the paper summarizes the challenges and the possibilities for the future work for real time container tracking solutions with the ubiquitous mobile and satellite network together with the high performance sensors and computer vision. All of those components combine to provide an excellent delivery of supply chain management with outstanding operation and security.

※ 이 논문은 2012년도 정부(교육과학기술부)의 재원으로 한국연구재단의 지원을 받아 수행된 연구임(No.2011-0029321)

※ 본 연구는 지식경제부 및 정보통신산업진흥원의 대학 IT연구센터 지원사업의 연구결과로 수행되었음(NIPA-2013-H0301-13-2005)

- 주저자 : 목포대학교 전자공학과, sharmaronesh@yahoo.com, 학생회원

교신저자 : 목포대학교 정보전자공학과, srlee@ mokpo.ac.kr, 정회원

논문번호 : KICS2013-01-021, 접수일자 : 2013년 1월 14일, 최종논문접수일자 : 2013년 3월 8일 
tracking and aims at securing assets and increasing operational efficiency of the container chain management and terminal yard ${ }^{[1]}$. With the rapid development of $\mathrm{M} 2 \mathrm{M}$ communication, a smart supply chain management is formed based on Radio Frequency Identification (RFID), sensors, high performance computer vision, intelligent technologies and nano technologies. The requirement for customers transporting goods and stuffs using containers now have moved from cost saving aspect to service based aspect, where the real time container tracking solutions are provided. A smart shipping container incorporates container chain management, data logging, and satellite positioning and data communication for real time tracking solutions.

The research related to the smart container shipping and data communication for real time operation are as follows: S. J. Kim ${ }^{[2]}$ proposed intelligent networked containers as a method to realize global smart chain management, but it was based on RFID technology and has the limitation that containers were managed through the data collected only in main logistics bases, not real-time communication in all the way to the destinations. C.Y. Lee ${ }^{[3]}$ researched into designing and realizing the transport protocol in large tag data on the system based on RFID, and W.S $\mathrm{Bae}^{[4]}$ researched into efficient authentication protocols by making use of eseal which is a container securing equipment based on RFID. RFID systems have been developed to identify containers with the recognition of serial code of the container ${ }^{[5]}$. Besides the latest technology ${ }^{[5]}$, the eseal which informs the customers on the location of the containers, the security of the container for example the opening/closing of the container, temperature, humidity by an email and SMS alert, but it is limited to cellular network coverage. However the above research shows that the detailed information for the transport chain is not available for end to end real time operation when the ship is in the ocean water where cellular network is not available and due to the high cost of satellite internet access. Furthermore the automatic recognition software has limitation for real time operation to recognize the container serial number at the terminal yard.

In this paper we firstly present an automatic identification system for recognizing the container at the terminal gate using acquisition tools and visual c++ software for real time operation. An emailing function which sends alerts to the customers on the arrival and departure of the container from the terminal yard. Secondly to use a cloud based web to update the container status using satellite based internet when the communication setup in the ship is not limited to cellular network coverage. This novel approach will make container supply chain management a real time end to end operation and will estimate the amount of data required to upload the container status data to the cloud when realizing the high cost of satellite internet.

\section{Overview of the System}

\subsection{Visual Studio 2010 and Opencv}

Visual studio is an integrated development environment from microsoft. It is used to develop console and graphical user interface applications along with windows forms applications, web sites, web applications, and web services ${ }^{[6]}$. Opencv is a library of programming functions mainly aimed at real-time computer vision, developed by Intel $^{[7]}$, and now supported by Willow and Itseez ${ }^{[7]}$. It is free for use under the open source BSD license. The library is cross-platform. It focuses mainly on real-time image processing. We integrate opencv libraries to visual studio to process container serial number segmentation and preprocessing algorithms and with visual studio on its own we create an email function.

\subsection{Tesseract OCR}

Tesseract is arguably the best free open source OCR engine available. It was originally developed by HP Labs between 1985 and 1995 but now has been taken over by Google ${ }^{[8]}$. We integrate tesseract library with visual studio to recognize 


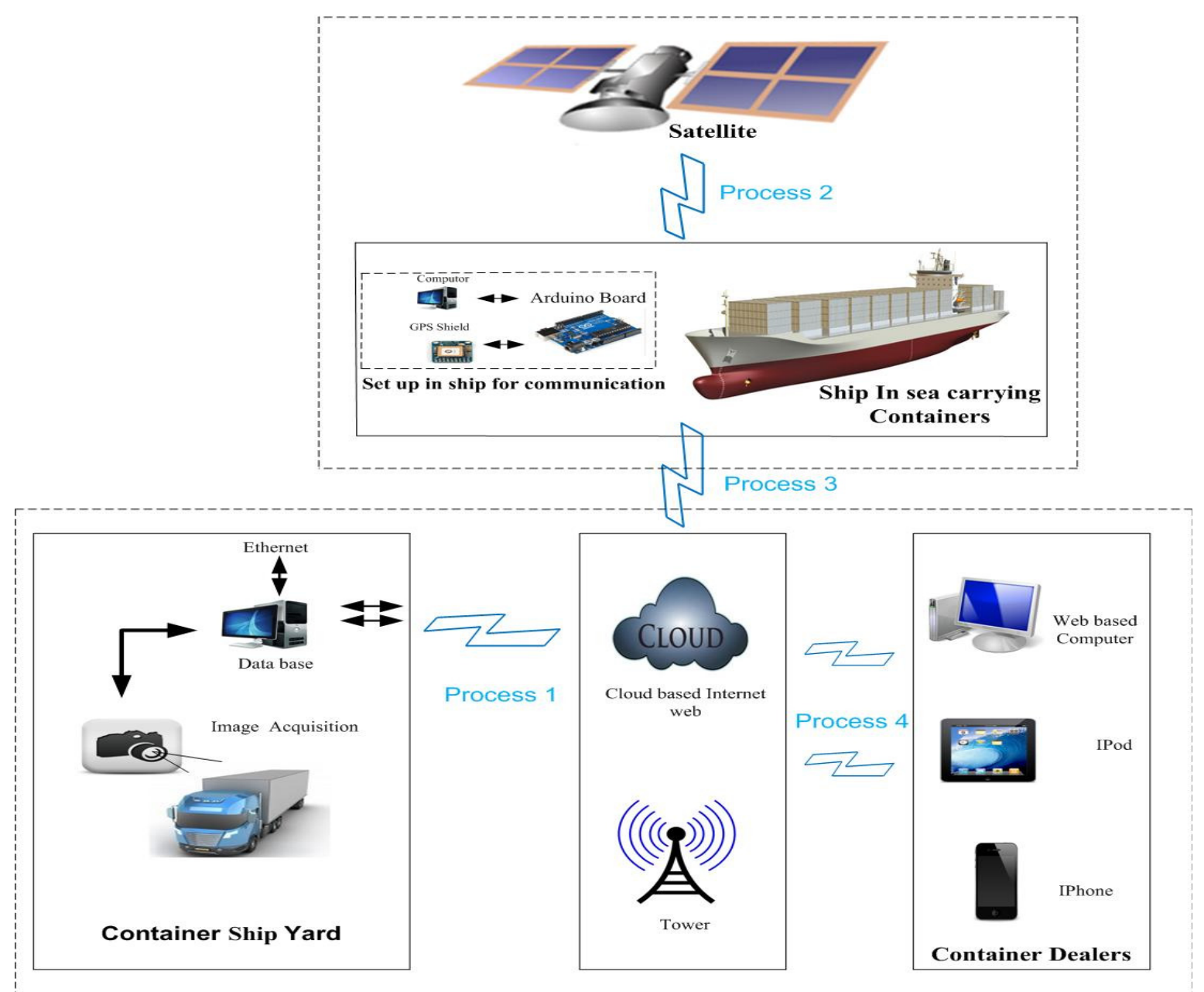

Fig. 1. Smart shipping container identification and tracking system

the container serial code and rely on tesseract to be able to accurately recognize a uniform font size of digits and alphanumeric characters The process for smart container identification and

The implemented system recognizes the containers and sends an email alert to the container customers on the arrival and departure of the containers at the terminal gate. While the ship carries the containers through the ocean waters and is not limited to cellular network, the communication setup in the vessel identifies its longitudes, latitude using GPS and other agent fault detection from the eseal ${ }^{[5]}$ installed in the container, then it uploads those data to the cloud based web. The database network setup at the container terminal extracts the data from the web and uses google map to locate the ship and sends tracking system is shown in Fig. 1.

\subsection{Proposed System}

an email to the container customers informing the location of their container or any other fault detected in the container in an interval of time. And as the ship is in the cellular network coverage, the previous alert is terminated and the automatic alert system installed in the container which is eseal sends the status and fault detection information to the customers at a regular interval by an email and SMS alert.

\section{Container Code Detection and Recognition}


For container identification, the current standard which deals with the coding, identification and marking of the containers is with the structure of ISO 6346 with 4 capital letters and 7 digits $^{[9]}$. Owner's code consisting of 3 capital letters, category identifier consisting of 1 capital letter and 6 numeric digits assigned by the owner which uniquely identifies the container and the last digit is the check digit. In order to identify the container, firstly container image segmentation is done, then code region detection and code format type is performed and finally preprocessing and recognition algorithm is processed to recognize the container, as shown in Fig. 2.

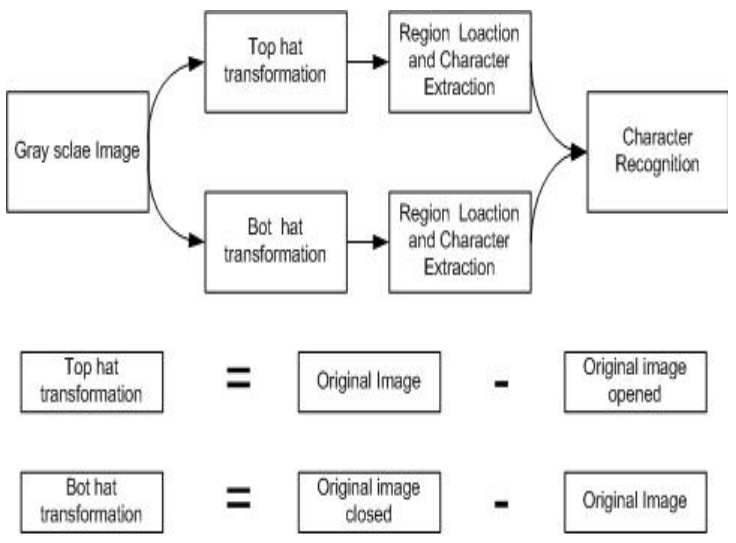

Fig. 2. Serial code recognition process

\subsection{Container Image Segmentation}

Segmentation is the process of eliminating the background of the image, as shown in Fig. 3a and Fig. $3 \mathrm{c}$ the container sample image, a segmentation algorithm needs to differentiate the code from the background of the image. To segment the image we take the approach of using top-hat and bot-hat transformation ${ }^{[10]}$, both transformations are developed from morphological operation, as shown in Fig. 3.

The transforms are aimed at extracting white color and black color characters respectively from the background color of the image ${ }^{[11]}$. These transforms are applied to the input container image depending on the code character color. The segmented image is then processed for region location and code character extraction.

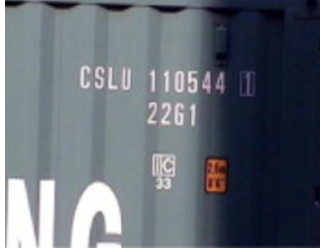

a) Container image

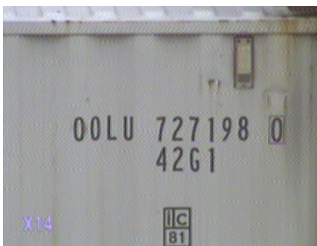

c) Container image

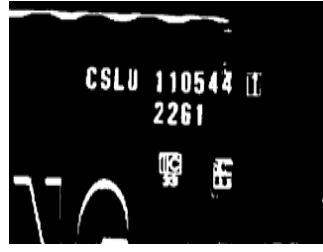

b) Segmented image

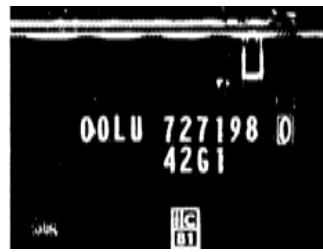

d) Segmented image
Fig. 3. Container serial code image segmentation

\subsection{Region Location and Code Format}

The container code segmented image is shown in Fig. $3 b$ and Fig. 3d, it contains many other objects apart from the serial code, therefore to locate the code region, firstly we transform the segmented image to a binary image. Connected component analysis is applied to each object for labeling and each label object is then filtered with the code character width and height threshold values to obtain only object of code character size. It can be possible for some other objects apart from the code characters to be detected in the process of width and height threshold as shown in Fig. 4a, therefore it is necessary to setup up second filter command with code length and height threshold, for this firstly using the morphological closing operation all the objects in the image is made horizontally connected as shown in Fig. 4b. Object length and width threshold is performed to eliminate any other unwanted objects. Fig. 4c shows the unwanted objects eliminated. For locating code region for vertical code format, a similar algorithm as used for horizontal code detection is performed by using vertical format code threshold values. To determine the code format morphological closing operation with different structuring element size is used to detect whether the input container code format is horizontal or vertical. Finally performing bounding box algorithm the code region is obtained.

Under certain circumstances the serial code 


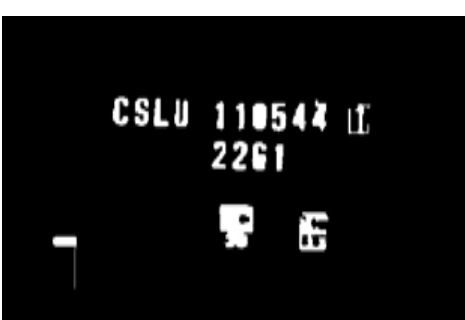

a) Width and height threshold

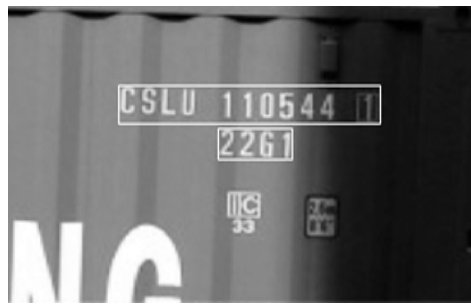

d) Code region located

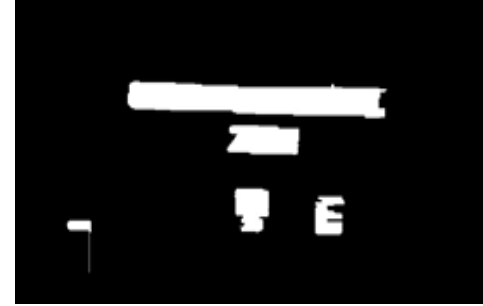

b) Morphological closing image

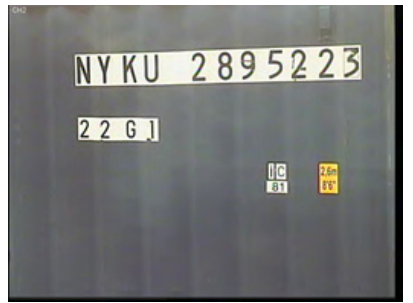

e) Skew container code image

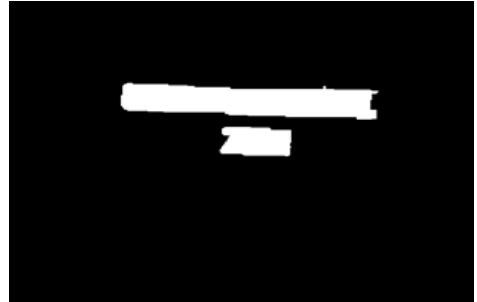

c) Code length and height threshold

Fig. 4. Container serial code detection and skew correction

sometimes turns to be skewed at an inclined angle as shown Fig. 4e, we apply rotated minimum bounding rectangle to those container code images as shown in Fig. 4e. The skew angle is determined and further to correct the skew, affine transformation and rectangle sub pixels is used to correct and relocate the code region. The corrected skew image is shown in Fig. 4g.

\subsection{Preprocessing Algorithm and Recognition}

The importance of the preprocessing technique is to enhance the code characters to overcome some of the factors which may affect the recognition accuracy such as the quality of the image depending on the climatology changes with the change in luminous condition. The system can be quite complex due to outdoor scene of the system. In our case morphological operation technique has been studied to represent the object. We used top-hat and bot-hat transformation to extract the code characters from the background of the extracted region, median filter to smooth the edges and morphological closing with the structuring element to further enhance the object to be recognized.

For the recognition of the serial code, in our case we use the tesseract OCR engine in the recognition process. The OCR algorithm is capable of recognizing line by line input, and single words, numbers, and characters as input. In our system, once the extracted region is preprocessed we extract each code character/number from the region. Using connected component analysis, each object can be detected and stored separately, the connected component analysis detects objects in horizontal direction then in vertical direction, in this process code characters/numbers can be detected randomly. Therefore we construct bounding box at each object, and take the $\mathrm{x}$ coordinate of the northwest corner of the all bounding boxes for horizontal format code and arrange them in ascending order, and taking the $y$ coordinate respectively for the northwest corner for the vertical format code. Now while taking the objects in ascending order of either $\mathrm{x}$ or $\mathrm{y}$ value of the bounding box, the problem of random selection of the code characters is solved. Besides each of those detected code characters and numbers are respectively fed to the OCR engine to be recognized.

\section{Automatic Alert System for Smart Container}

\subsection{At Container Terminal Yard}

As the truck loaded with container either arrives or departs from the container terminals, at the gate the container image is processed for the 
code recognition as shown in Fig. 5 (a). The end user cross checks the code, if it is wrongly recognized, then the user is given the chance to enter the code else if it is correct, the time and date is noted and the application ask the user whether the container is discharged or will be shipped to another destination. If the container is discharged, the container information is already stored in the database and the system automatically generates an email alert to the container customer on the discharge of the container from the terminal. On the other hand if the container arrives for shipment, at a later stage the container content is updated in the database and an automatic email alert is generated to the container customers on the arrival and further loading of the container on the vessel.

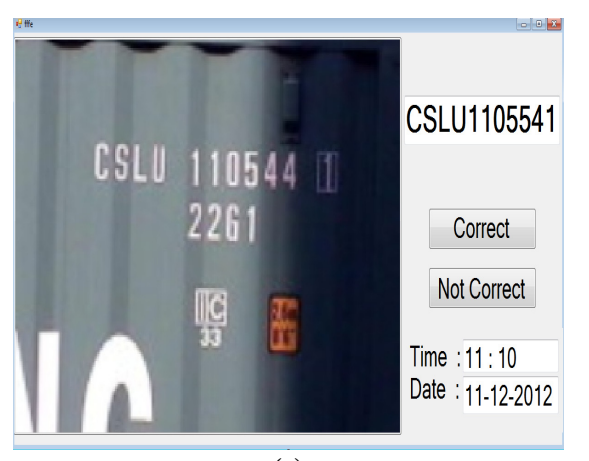

(a)

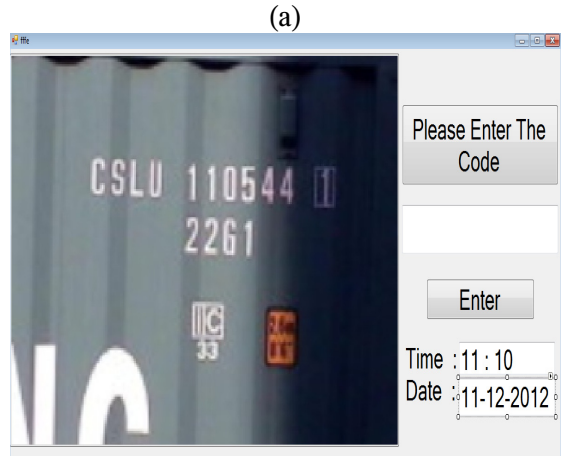

(b)

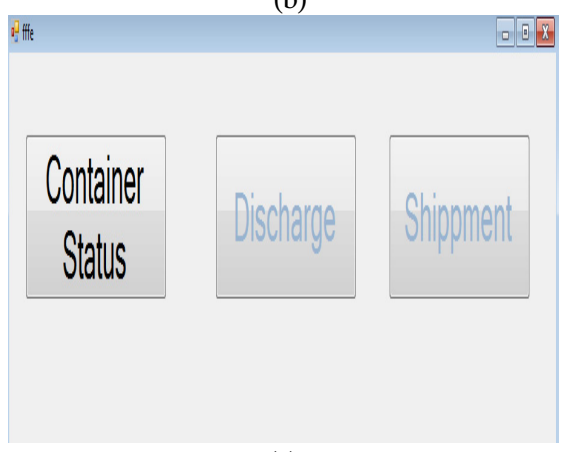

(c)

Fig. 5. Application for container terminals

\subsection{In Cellular Network Coverage Area}

Current real-time container tracking system for supply chain management introduced here is a device attached to the inside of the container carrying the real-time container tracking equipment as shown in Fig. $6^{[13]}$. It detects the information of location and state (temperature, humidity, vibration and the opening and shutting of the door) of the container carrying the equipment in real time ${ }^{[2,5]}$. In this container tracking system, the communication technologies applied to the real-time container tracking device are GSM methods, and the location and time information of the device is acquired by using Global Navigation Satellite System (GLONASS) and GPS ${ }^{[5]}$. As the device enters the cellular network region it sends its status data to the base station and further to the customer's mobile through $\mathrm{SMS}^{[2]}$. If there is an interrupt for the door opening or closing an alert is sent instantly and if not in cellular network coverage, the interrupt is stored in the memory and waits for next cellular network coverage for SMS to be sent ${ }^{[2]}$. As container customers can track the information such as the location of the container and the temperature, humidity and door opening/shutting of the inside of the container, they are able to make proper decisions for global supply chain management, however the automatic alert is only limited to cellular network coverage and is not available when the ship is on the open sea. This limitation avoids the supply chain management from being fully real time operation.

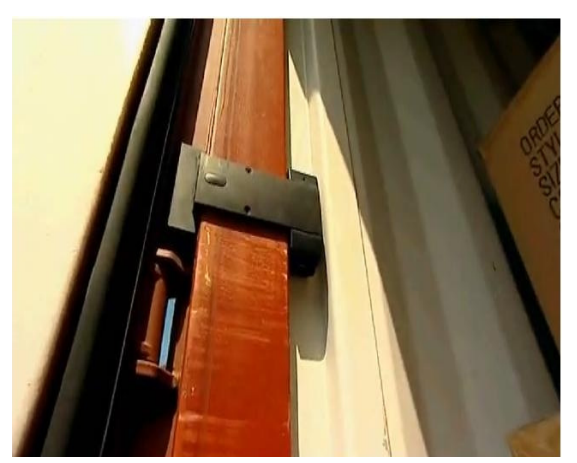

(a)Tracking device [5] 


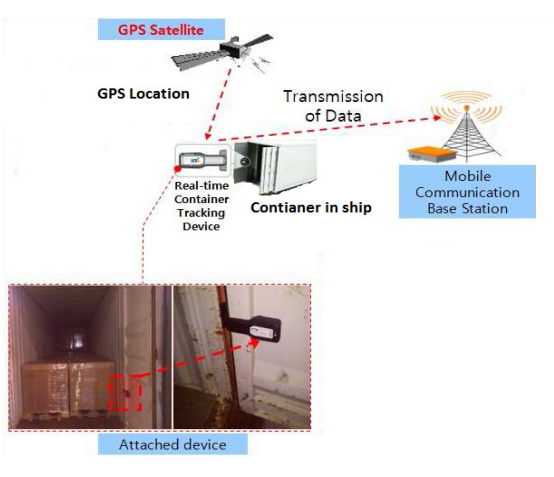

(b)Automatic alert process[2]

Fig. 6 Device and process for automatic alert in cellular network coverage

\subsection{Ship Not Limited to Cellular Network Coverage}

As mentioned in the earlier section the real time container tracking device is only limited to a cellular network to generate automatic alerts and alerts are not available otherwise. When the ship is out of the cellular network region all information is stored till next cellular network coverage is detected and then normal alerts are sent with agent faults if detected. To make supply chain management fully real time monitoring system, in this research work we study and realize communication protocol and ways to analysis the cost of making the supply chain a real time operation. Firstly, we propose to use a reader which determines the availability of the cellular network coverage and receives agent fault detection information from the eseal installed in the container in unavailability of the cellular network. Secondly to use GPS setup to enquire the latitude and longitude information and to upload this together with the fault detection to cloud based web. This process of uploading will only be done when the ship is not in the cellular network coverage.

The emailing application system integrated with the automatic recognition application at the container terminal extracts the data uploaded to the cloud based web and sends periodical alerts to the container customers on the location and the fault detection information with the email application. This status information data is uploaded and extracted at an interval of time and for agent fault detection, as the fault is detected the information is uploaded and extracted on the instance and customers get the alert.

\section{Implementation}

Firstly, we integrate opencv and OCR libraries to visual studio 2010 to perform container code recognition at the container terminal yard. Emailing function is written in visual $\mathrm{c}^{++}$script and is combined with the recognition algorithm to send automatic email alerts to the container customers on the arrival and discharge of the container as mentioned in the previous section.

Secondly, the current container tracking device installed in the shipment container only sends automatic alerts and interrupt alerts whenever the container vessels are in cellular network coverage area. In this paper we propose to implement an automatic interrupt and location alert whenever the vessel is out of cellular network coverage. The proposed system set up in the ship is achieved by using a GPS board with data logging, arduino UNO, ethernet shield, reader for cellular network and a receiver for receiving the fault interrupt from the eseal installed in the container. On the container terminal side, a SQL server to store information, and an emailing function to give periodical alerts to be integrated with the recognition application. Due to time constraints for this paper this proposed method was not experimented and tested fully, we leave it to be done in our future.

\section{Results and Discussion}

The designed system implemented in this paper, firstly realizes a real time automatic application for container serial code identification and recognition when compared to other software such as matlab where the application simulates manually or through a server. We processed images taken under reasonable lighting conditions by image acquisition, 54 images were of good quality and 334 of medium quality images. The 
region location algorithm showed accuracy of 96 $\%$ for average good quality images and $91 \%$ for images with missing characters, damaged containers, blurry images, extra marks on the container, and with uneven position of the acquisition system. For 54 good quality images the extracted code was fed to OCR engine, table 1 shows the recognition accuracy for individual characters. At first we counted the total number of occurrences for each characters in 52 successfully segmented images. For each character the recognition rate for being correctly recognized was calculated with the proportion of the number of correctly recognized characters to the total number of occurrences. The average recognizing rate was $89 \%$. Moreover the recognition rate for some characters was very low, for example $0, \mathrm{~B}$, $\mathrm{D}, \mathrm{G}$ and $\mathrm{R}$ from other characters. This may be due to low sample size, the normalize character size, and the characteristic appearance and character thickness. Furthermore the recognition was achieved using the tesseract OCR, and it contained its own english training data set, however to further increase our recognition rate, the OCR engine needs to be trained with the character sample images and using more sample images the recognition rate is supposed to be increased.

Secondly the emailing function correctly sends email alerts to the container customers on the status of the container while the containers are in and out of the terminal yard. The above two algorithms of recognition and email alert proves to improve the productivity and security of the container supply chain management.

Moreover, to develop a real time end to end supply chain, the cost of data communication needs to be analyzed for using satellite internet when cellular network is not available. In our future work will analyze the average amount of data required for using the proposed system on a real time application.
Table 1. Recognition for Individual Characters

\begin{tabular}{|c|c|c|c|}
\hline Character & $\begin{array}{l}\text { Number of } \\
\text { occurrences }\end{array}$ & $\begin{array}{l}\text { Number of } \\
\text { correct } \\
\text { recognition }\end{array}$ & $\begin{array}{l}\text { Recognition } \\
\text { rate } \%\end{array}$ \\
\hline 0 & 46 & 36 & 78 \\
\hline 1 & 38 & 32 & 84 \\
\hline 2 & 30 & 30 & 100 \\
\hline 3 & 26 & 26 & 100 \\
\hline 4 & 44 & 40 & 90 \\
\hline 5 & 30 & 28 & 93 \\
\hline 6 & 32 & 22 & 69 \\
\hline 7 & 18 & 16 & 88 \\
\hline 8 & 36 & 30 & 83 \\
\hline 9 & 20 & 20 & 100 \\
\hline A & 15 & 15 & 100 \\
\hline B & 18 & 12 & 66 \\
\hline $\mathrm{C}$ & 15 & 15 & 100 \\
\hline $\mathrm{D}$ & 24 & 16 & 66 \\
\hline $\mathrm{E}$ & 10 & 10 & 100 \\
\hline $\mathrm{F}$ & 0 & 0 & None \\
\hline G & 18 & 12 & 66 \\
\hline $\mathrm{H}$ & 12 & 12 & 100 \\
\hline I & 15 & 15 & 100 \\
\hline $\mathrm{J}$ & 0 & 0 & None \\
\hline $\mathrm{K}$ & 9 & 9 & 100 \\
\hline $\mathrm{L}$ & 12 & 10 & 90 \\
\hline M & 17 & 17 & 100 \\
\hline $\mathrm{N}$ & 20 & 20 & 100 \\
\hline $\mathrm{O}$ & 0 & 0 & None \\
\hline $\mathrm{P}$ & 19 & 19 & 100 \\
\hline Q & 0 & 0 & None \\
\hline $\mathrm{R}$ & 14 & 8 & 66 \\
\hline $\mathrm{S}$ & 9 & 9 & 100 \\
\hline $\mathrm{T}$ & 18 & 18 & 100 \\
\hline $\mathrm{U}$ & 16 & 15 & 93 \\
\hline $\mathrm{V}$ & 0 & 0 & None \\
\hline W & 10 & 10 & 100 \\
\hline $\mathrm{X}$ & 7 & 6 & 85 \\
\hline $\mathrm{Y}$ & 8 & 8 & 100 \\
\hline $\mathrm{Z}$ & 0 & 0 & None \\
\hline \multicolumn{3}{|c|}{ Average Recognition rate } & $89 \%$ \\
\hline
\end{tabular}

\section{Conclusion}

Through real time monitoring of the container in shipment, the container is fully tracked with the security information. There are different ways to improve the monitoring of container but the technologies are limited. In this paper a reasonable application was developed for real time monitoring with the container identification and automatic email 
alert to increase the productivity and security of the container chain management. With this robustness and improved performances, this application should be more convenient compared to other similar applications which require manual tools for real time application. For the supply chain management to be in real time operation as proposed in this paper, the data required to upload the contents to the cloud web plays an important factor to determine the efficiency and productivity of the supply chain management for full real time tracking solutions.

\section{References}

[1] H. Cho and J. Puthenkulam, "Machine to machine (M2M) communication study report," IEEE 802.16ppc-10/0002r6, May 2010.

[2] J. J. Shin and H. R. Choi, "A study on data communicating method of real time based container tracking system," Int. J. Multimedia Ubiquitous Eng. (IJMUE), vol. 7, no. 2, pp. 201-207, Apr. 2012.

[3] C. Y. Lee and H. K. Hong, "A study of the message protocols technologies in M2M platforms," J. Korea Inform. Commun. Soc. (KICS), vol. 35, no. 1, pp. 53-61, Jan. 2010.

[4] W. S. Bae, S. Y. Lee, and Y. J. Kim, "An efficient authentication protocol for e-Seal security," Autumn Conf. Korea Academia-Indust. Cooperation Soc. (KAIS), pp. 591-593, Seoul, South Korea, Dec. 2009.

[5] G. T. Technology (2012), GPS container tracking [Online], retrieved (2012, Dec), available: http://globaltrackingtechnology.com/.

[6] Wikipedia (2012), Microsoft visual studio [Online], retrieved (2012, Dec 30), available: http://en.wikipedia.org/wiki/Microsoft_Visual_ Studio.

[7] Wikipedia (2012), OpenCV [Online], retrieved (2012, Dec), available:

http://en.wikipedia.org/wiki/OpenCV.

[8] G. P. Hosting (2012), Tesseract-ocr [Online], retrieved (2012 Dec 25), available: http://code.google.com/p/tesseract-ocr/.

[9] Wikipedia (2012), ISO 6346 [Online], retrieved (2012 Dec 25), available: http://en.wikipedia.org/wiki/ISO_6346.

[10] I. S. Igual, A. P. Jimenez, and G. A. Garica, "Preprocessing and recognition of characters in container codes," in Proc. 16th Int. Conf. Pattern Recognition, vol. 3, pp. 143-146, Aug. 2002.

[11] K. Koo and E. Cha, "A novel container ISO-code recognition method using texture clustering with a spatial structure window," Int. J. Advanced Sci. Technol. (IJAST), vol. 41, pp. 83-92, Apr. 2012.

[12] H. C. Chen, C. K. Chen, and F. Hsu, "A computer vision system for automated container code recognition," in Proc. Int. Multi Conf. Eng. and Comput. Scientists (IMECS 2011), pp. 470-474, Hong Kong, Mar. 2011.

[13] M. M. Gil, P. Espineira, and M. Juan, "Supply chain management in automotive international logistics," J. Syst. Manage. Sci. (JSMS), vol. 1, no. 4, pp. 80-96, Aug. 2011.

[14] R. Shetty, and R. Caceres, "Optical container code recognition and its impact on the maritime supply chain," in Proc. Ind. and Syst. Eng. Research Conf. (ISERC 2012), Florida, U.S.A., May 2012.

[15] A. C. Skorna and C. Bode, "Risk and loss prevention within the transport chain," 20th Int. Conf. Manage. Tech. (IAMOT 2011). Florida, U.S.A., Apr. 2011.

[16] W. Wu, Z. Liu, and M. Chen, "An automated vision system for container-code recognition," Int. J. Expert Syst. Applicat. (ESWA), vol. 39, no. 3, pp. 2842-2855, Feb. 2012. 
로네쉬 샤르마 (Ronesh Sharma)

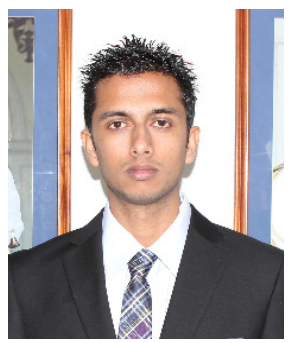

Nov. 2007 BE of Bachelor of Engineering Technology

from University of the South Pacific, Fiji

Sep. $\quad 2011 \sim$ present $\quad$ MS

Student, Dept. of

Electronics Engineering,

University of Mokpo, South Korea.

$<$ Research Area $>$ Image Processing, Pattern

Recognition, Wireless Communication, M2M and Robotics application

이 성 로 (Seong Ro Lee)

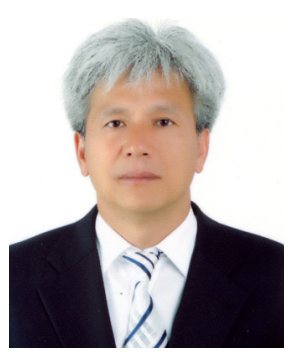

1987년 2월 고려대학교 전자 공학과 공학사

1990년 2월 한국과학기술원 전기및전자공학과 공학석사 1996년 8월 한국과학기술원

전기및전자공학과 공학박사 1997년 9월 현재 목포대학교 공과대학 정보전자공학과 교수

<관심분야> 디지털통신시스템, 이동 및 위성통신시 스템, USN/텔레매틱스응용분야, 임베디드시스템 